\title{
Transcutaneous Cancer Vaccine using a Reverse Micellar Antigen Carrier
}

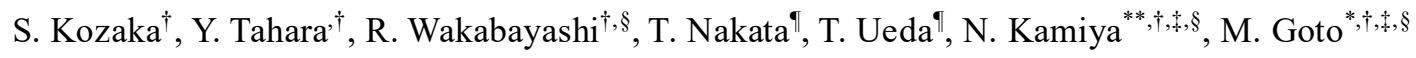

$\left[{ }^{\dagger}\right]$ Department of Applied Chemistry, Graduate School of Engineering, Kyushu University, Motooka 744, Nishi-ku, Fukuoka 819-0395, Japan,

$\left[{ }^{\ddagger}\right]$ Advanced Transdermal Drug Delivery System Center, Kyushu University, Motooka 744, Nishiku, Fukuoka 819-0395, Japan,

$\left[{ }^{\S}\right]$ Center for Future Chemistry, Kyushu University, Motooka 744, Nishi-ku, Fukuoka 819-0395, Japan,

["] Kobayashi Pharmaceutical Co., Ltd. 1-30-3 Toyokawa, Ibaraki, Osaka 567-0057, Japan

\author{
*Corresponding Author \\ TEL: +81928022806. \\ FAX: +81928022810. \\ E-mail: m-goto@mail.cstm.kyushu-u.ac.jp.
}



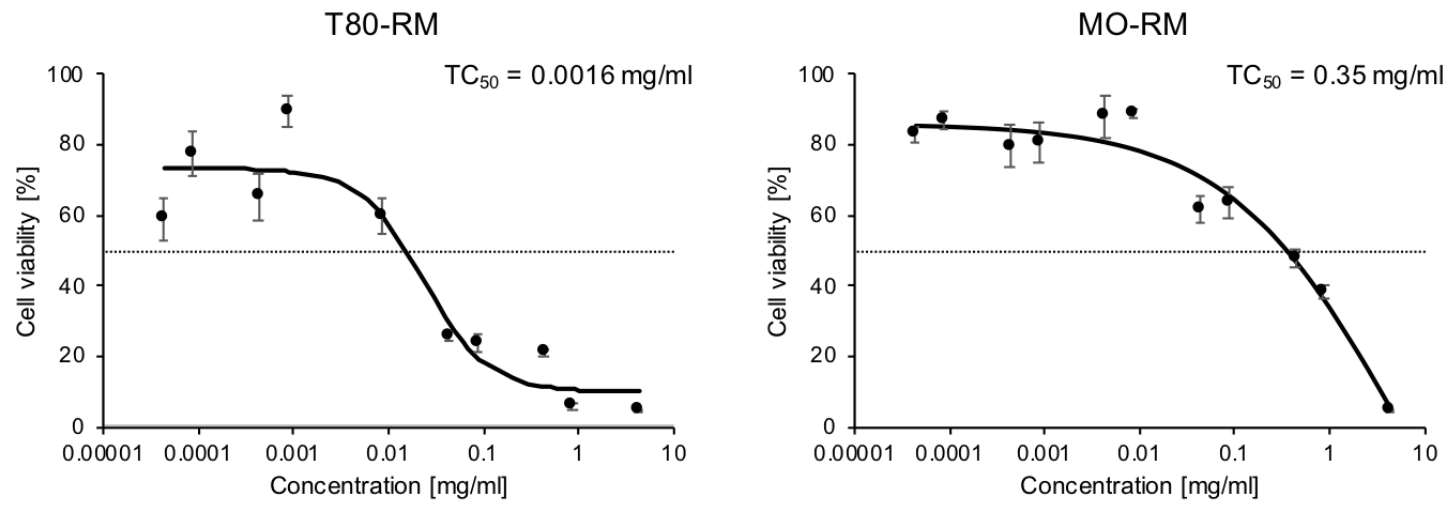

Figure S1. Cytotoxicity of K-TRP-2 loaded RMs on DC2.4 cells. Cells were seeded on into a 96well plate $\left(1.0 \times 10^{4}\right.$ cells/well $)$ and incubated at $37^{\circ} \mathrm{C}$ for $24 \mathrm{~h}$. After the addition of K-TRP-2 loaded RMs, the cells were incubated for another $24 \mathrm{~h}$. Cell viability was measured using WST - 8 assay. IC50 of T80-RM and MO-RM were calculated as $0.0016 \mathrm{mg} / \mathrm{ml}$ and $0.35 \mathrm{mg} / \mathrm{ml}$, respectively. $n=5$, mean \pm SE. 


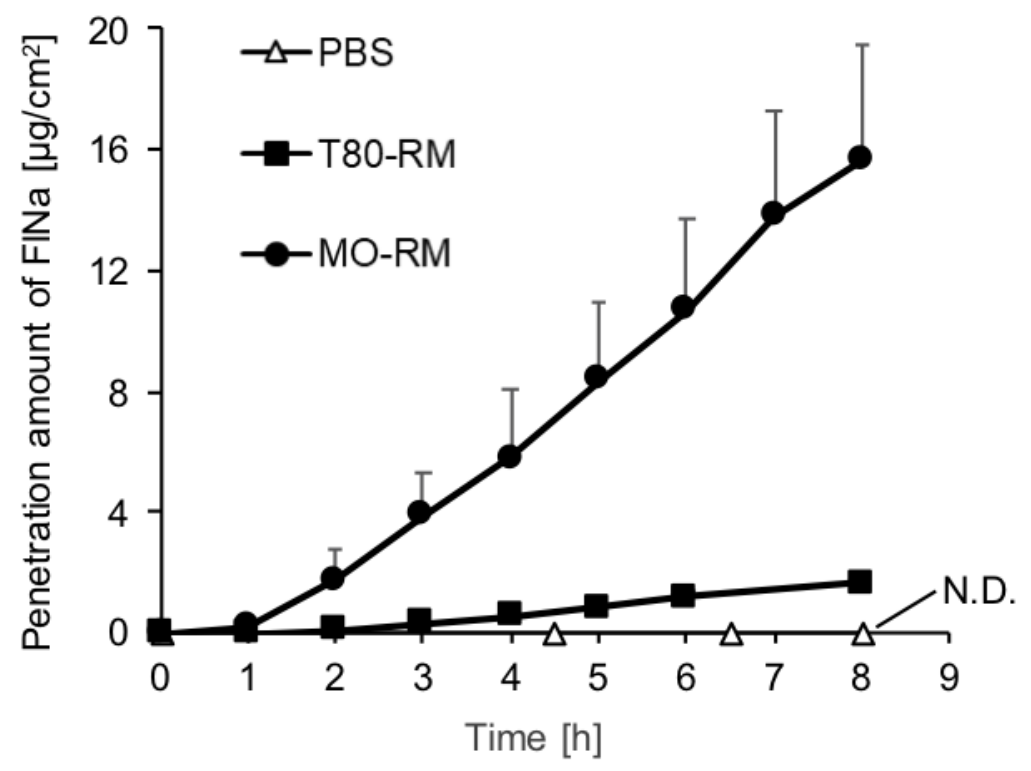

Figure S2. Cumulative amount of FlNa penetrated through mouse skin. The skin was treated with 200 $\mu$ of FINa loaded PBS solution, T80-RM, and MO-RM ([FINa] $=1 \mathrm{mg} / \mathrm{ml})$. The receiver phase of Franz diffusion cell was collected and FINa was quantified by fluorescent intensity. $n=3$, mean $\pm \mathrm{SE}$, N.D. stands for Not Detectable. 
Table S1. Skin permeation parameters of FITC-K-TRP-2 calculated with Lag-time method. $n=3$, mean \pm SE.

\begin{tabular}{lllll}
\hline & Flux & Lag-time & KSC & DsC \\
& {$\left[10^{-8} \mathrm{~g} / \mathrm{cm}^{2} / \mathrm{s}\right]$} & {$[\mathrm{h}]$} & $\begin{array}{l}\text { L } \\
{[-]}\end{array}$ & - \\
\hline PBS sol. & - & - & - & - \\
T80-RM & - & - & - & \\
MO-RM & $7.8 \pm 2.1$ & $4.8 \pm 0.3$ & $2.7 \pm 0.9$ & $2.7 \pm 0.2$ \\
\hline
\end{tabular}


Table S2. Skin permeation parameters of FINa calculated with Lag-time method.

$$
n=3 \text {, mean } \pm \text { SE. }
$$

\begin{tabular}{ccccc}
\hline & $\begin{array}{c}\text { Flux } \\
{\left[10^{-8} \mathrm{~g} / \mathrm{cm}^{2} / \mathrm{s}\right]}\end{array}$ & $\begin{array}{c}\text { Lag-time } \\
{[\mathrm{h}]}\end{array}$ & $\begin{array}{c}\mathrm{K}_{\mathrm{SC}} \\
{[-]}\end{array}$ & $\begin{array}{c}\mathrm{D}_{\mathrm{SC}} \\
{\left[10^{-8} \mathrm{~cm}^{2} / \mathrm{s}\right]}\end{array}$ \\
\hline PBS sol. & - & - & - & - \\
T80-RM & $8.4 \pm 1.5$ & $2.0 \pm 0.2$ & $72 \pm 9$ & $4.4 \pm 0.3$ \\
MO-RM & $63 \pm 14$ & $1.4 \pm 0.3$ & $543 \pm 20$ & $5.4 \pm 1.2$ \\
\hline
\end{tabular}




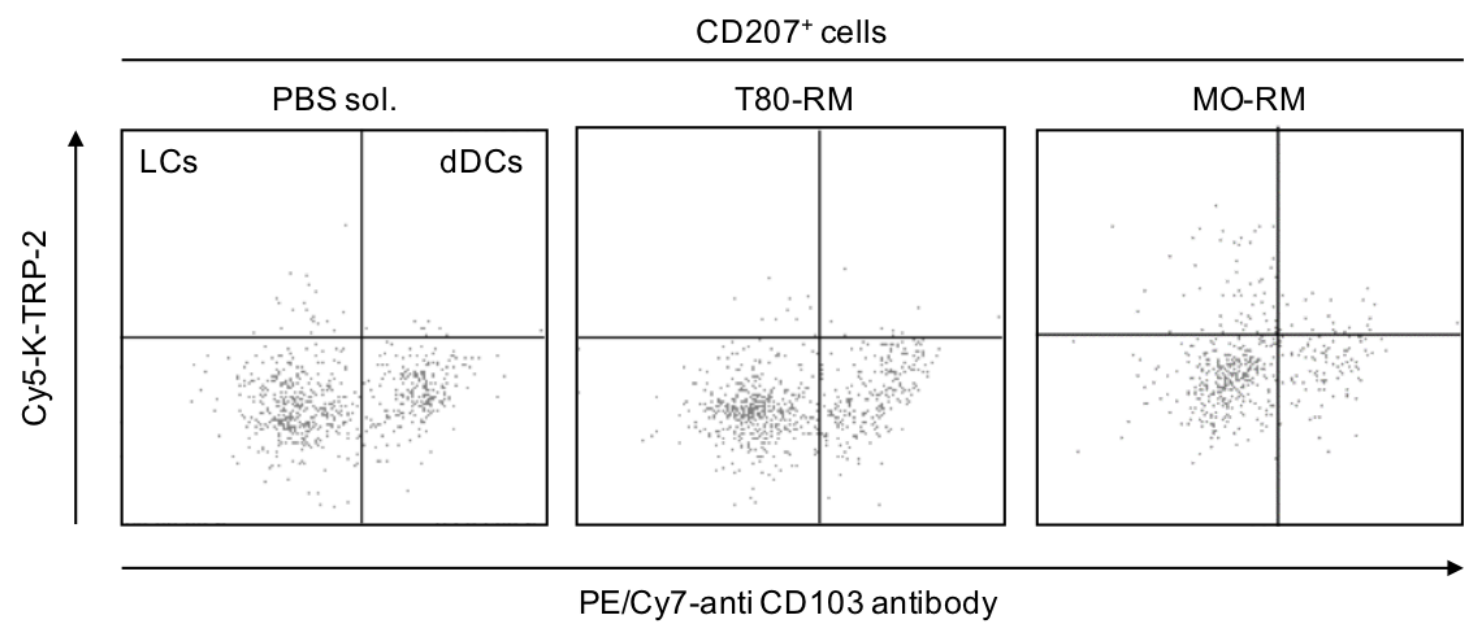

Figure S3. Flow cytometric analysis of CD207 ${ }^{+}$cells. PBS sol., T80-RM and MO-RM were applied onto the back of $\mathrm{C} 57 \mathrm{BL} / 6 \mathrm{~N}$ mouse for $6 \mathrm{~h}$. The skin was harvested and separated into single cells for flow cytometric measurement. The skin cells were stained using their surface markers, CD207 and $\mathrm{CD} 103$. In total, $1.5 \times 10^{5}$ skin cells, including keratinocytes, $\mathrm{CD} 207^{+}$cells and $\mathrm{CD} 207^{+} \mathrm{CD} 103^{+}$cells were analyzed. 
(A)

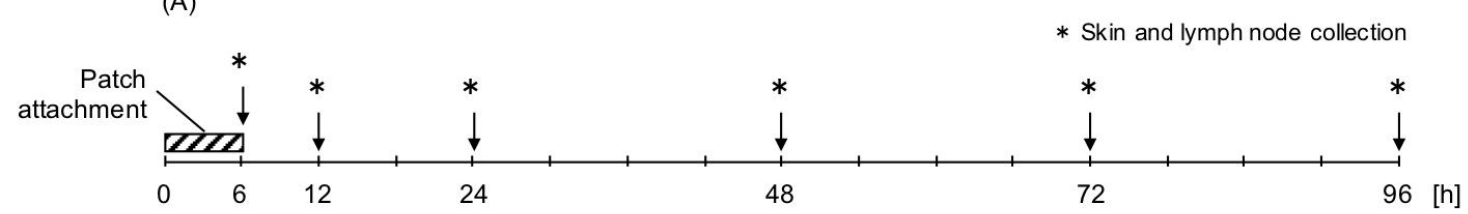

(B)
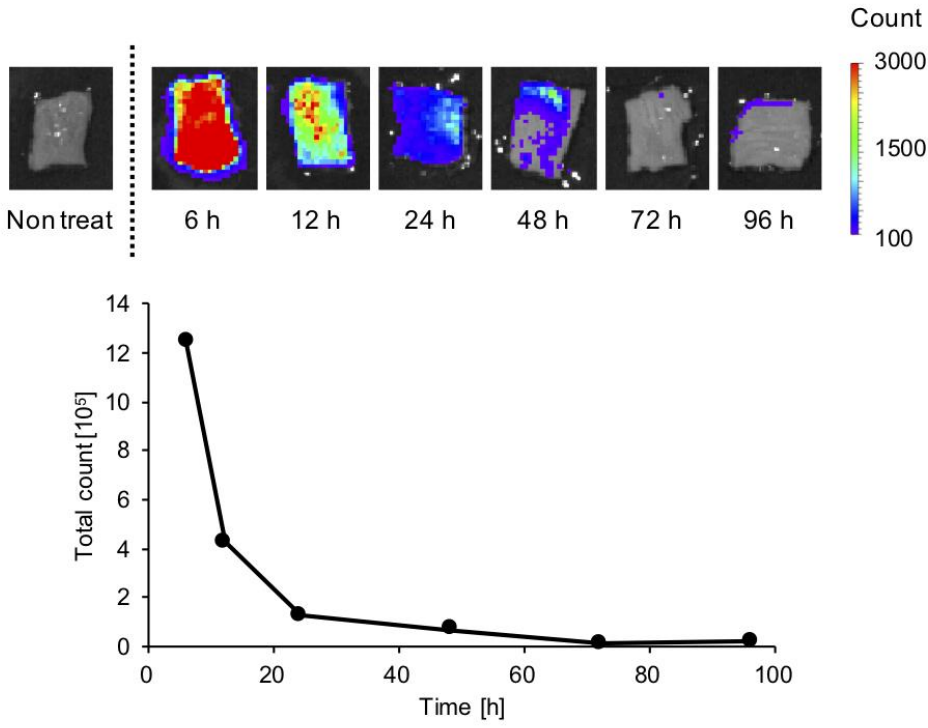

(C)
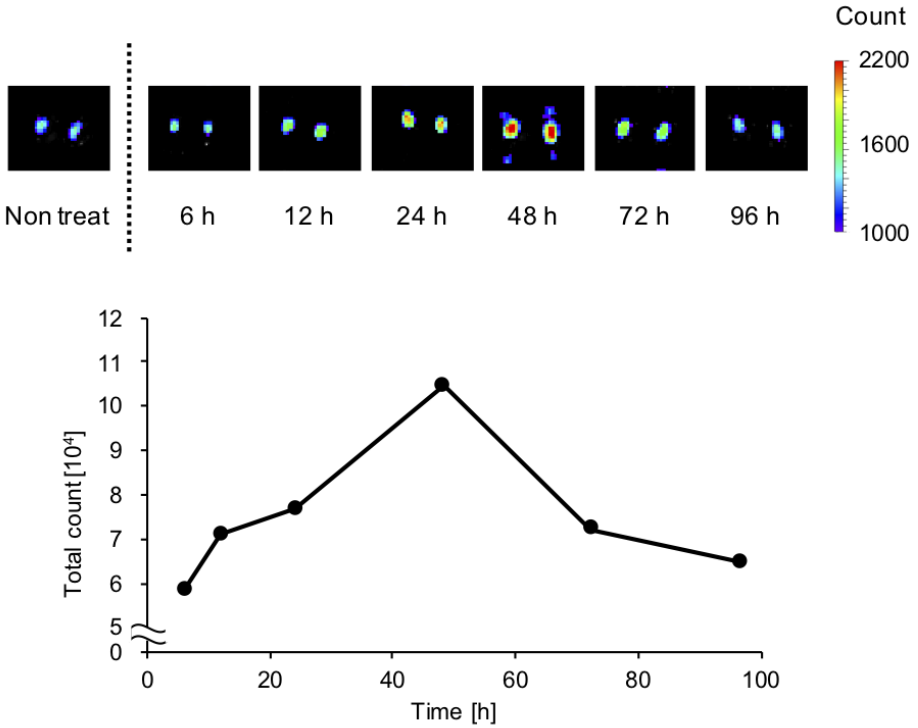

Figure S4. Antigen pharmacokinetics after transcutaneous application of MO-RM. (A) The time course of this experiment. A patch loading MO-RM was attached to the back of a mouse and removed after $6 \mathrm{~h}$. The back skin and the inguinal lymph nodes (ILNs) in both sides were collected. Fluorescence images of the skin (B) and ILNs (C). The graphs below show the fluorescence intensities in region of interest. $n=1$. 


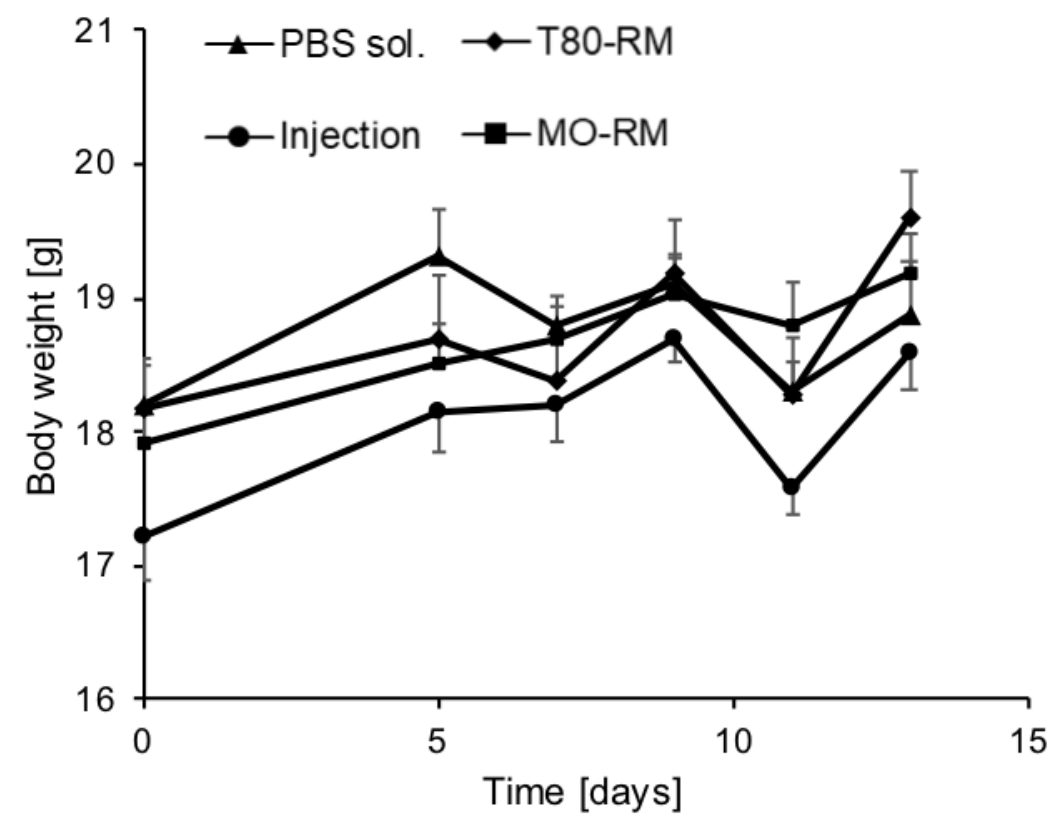

Figure S5. Body weight of tumor-bearing mice. $n=6$, mean \pm SE. 


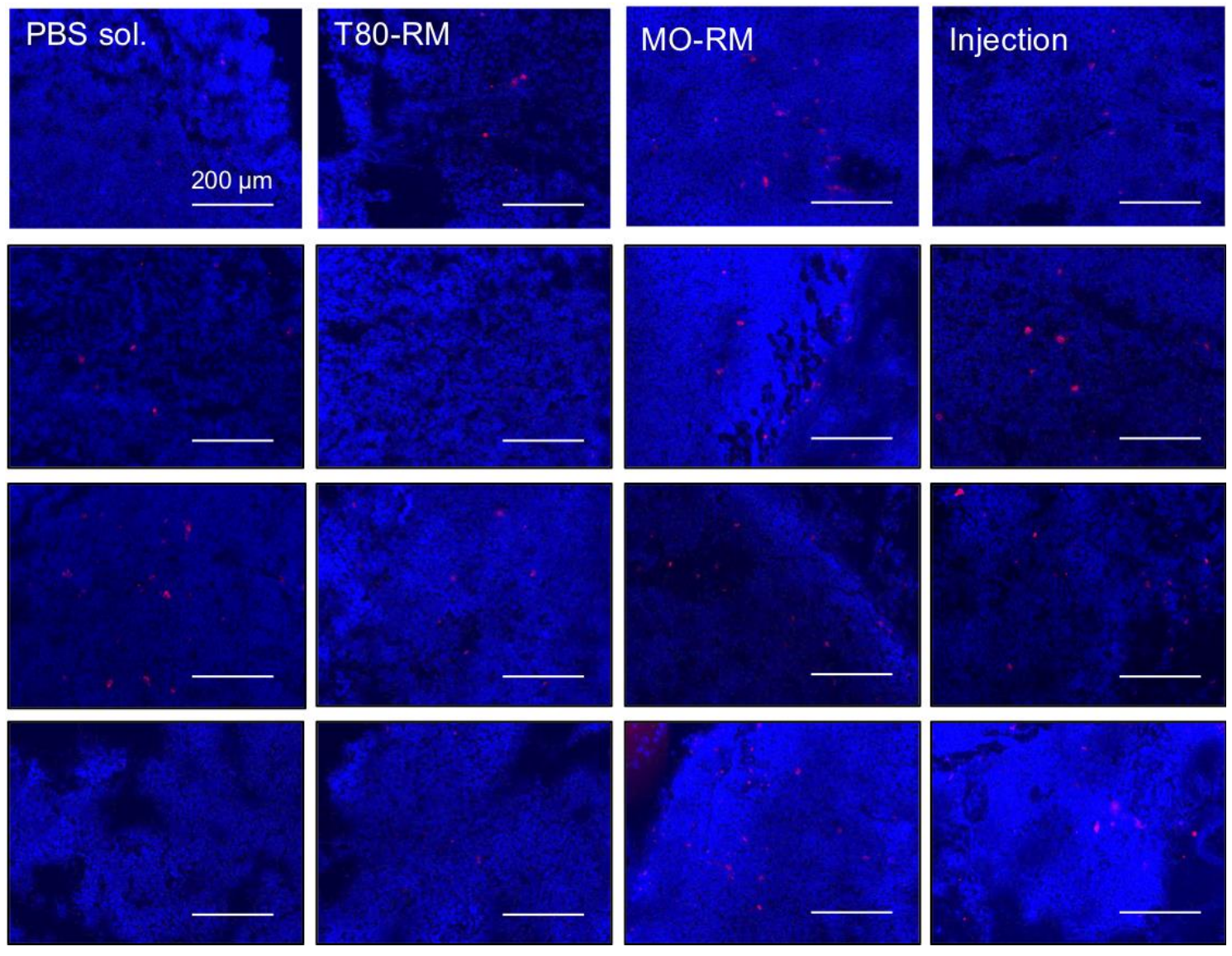

Figure S6. All of the fluorescent images of tumor cross sections. Scale: $200 \mu \mathrm{m}$. 